\title{
Thermoanalytical studies (TG-DTG-DSC, Py-GC/MS) of sodium carboxymethyl starch with different degrees of substitution
}

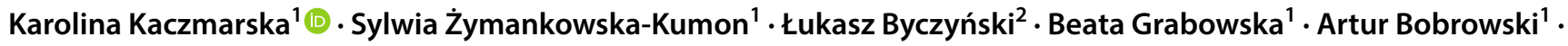 \\ Sylwia Cukrowicz ${ }^{1}$
}

Received: 17 November 2018 / Accepted: 2 October 2019 / Published online: 2 November 2019

(c) The Author(s) 2019

\begin{abstract}
The paper presents the results of thermal analysis of polymer material in the form of starch derivatives in the form of sodium carboxymethyl starch (CMS-Na) with degree of substitution (DS) in the range $0.2-0.9$ for the preparation of foundry binder. In this work, the thermal behavior of the modified starch and qualitative assessment of degradation products released during pyrolysis were determined and comprised. The analysis of the course of progressive decomposition of the starch material under controlled heating in the range of $25-1000{ }^{\circ} \mathrm{C}$ in anaerobic atmosphere was based on the results of thermal analysis methods (TG-DTG-DSC) in combination with the results of pyrolysis-gas chromatography-mass spectrometry (Py-GC/ MS). The detailed TG-DTG-DSC analysis allowed to determine and compare the temperature at which the process of decomposition of carboxymethyl starches sodium salts with different degrees of substitution begins and to determine the course of its degradation under conditions corresponding to the contact of the foundry binder in the form of starch material with liquid metal (conditions like in foundry mold). Thermogravimetric analysis shows that decomposition processes are multistage, and dehydration is the first step of decomposition. Moreover, TG-DTG-DSC analyses indicate that the thermal stability and the decomposition path of tested compounds depend on the DS. Results of Py-GC/MS studies showed that the formation of decomposition products (including cyclic and aromatic hydrocarbons) in a predetermined temperature range is lower in the case of CMS-Na with high DS.
\end{abstract}

Keywords Polymer · Sodium carboxymethyl starch · TG-DTG-DSC $\cdot$ Py-GC/MS · Thermal degradation · Foundry binders

\section{Introduction}

In the foundry industry in the production cycle, it is possible to use organic, inorganic and mineral substances, which, as binding materials, ensure obtaining durable casting forms based on the mineral matrix, at the same time giving the possibility of making castings with the reduction in their defects. Binders in sand molds are a key component determining their properties and produced castings quality by the binding strength of the of the matrix grains of sand. However,

Karolina Kaczmarska

karolina.kaczmarska@agh.edu.pl

1 Faculty of Foundry Engineering, AGH University of Science and Technology, Reymonta 23, 30059 Kraków, Poland

2 Department of Polymers and Biopolymers, Faculty of Chemistry, Rzeszow University of Technology, Al. Powstańców Warszawy 6, 35-959 Rzeszow, Poland some of these materials may be harmful to the environment during the technological process, even in their initial form. Therefore, a lot of research work is focused on the modification of materials or the development of new substances toward the development of environmentally friendly casting technologies [1-5]. The scientific work on the development of non-toxic and degradable binders also seems to be stimulated by the progress in research on modification of natural polymers, e.g., native starch, which has been observed in recent years. Poor properties of bonding sand by native starch-based binders show that they are not a suitable alternative to the currently used commercial binding materials from technological reasons $[6,7]$. But many works carried out in the field of application of natural polymers in foundry materials engineering prove that it is the modified form of starch that can provide a certain alternative to harmful components currently used in mold technology, while at the same time ensuring that molding sands with appropriate strength and 
performance parameters are obtained [2, 3, 5, 8]. Despite the constantly increasing possibilities of using starch derivatives, many aspects related to the process of their obtaining, crosslinking and degradation have remained unexplained. Moreover, the influence of the modification method, e.g., on the thermal properties of binders in the form of modified starch in relation to the application in foundry processes, is still studied.

In our work, the sodium carboxymethyl starch (CMS-Na), obtained by potato starch etherification, was chosen as the subject of research. During the chemical modification of natural starch, hydroxyl groups with carboxymethyl groups (with hydrophilic properties) are substituted in the rest of the glucopyranose rings. The number of substituted hydroxyl groups can be controlled quantitatively, and the effect of the modification process is characterized by the degree of substitution (DS) $[9,10]$. It results from the literature research that the hydrophilic group (with -COONa) share in the CMS-Na stems results in beneficial changes in the properties of the modified starch obtained. For example, the process of starch carboxymethylation already ensures its solubility in cold water and at the same time increases adhesion properties [11-14].

Due to the degree of substitution, the sodium carboxymethyl starch is classified into three groups, as starch derivatives with low degree of substitution: $\mathrm{DS}<0.3$; with medium degree of substitution: DS in the range of 0.3-0.7; with high substitution degree: DS in the range of 0.7-1.4 [15-18].

Results of research on foundry applications of sodium carboxymethyl demonstrated that with increasing DS of modified starch, it is possible to increase the strength of molds and its other properties [2, 6, 19, 20]. In our own research, CMS-Na was successfully used as a water-soluble binder for molding sands susceptible to both chemical and physical crosslinking (by conventional heating and exposure to electromagnetic radiation) $[5,6,8]$.

From the point of view of pouring a liquid alloy casting into foundry sand molds, important issue is it is to determine the thermal stability of a binder during process. Namely, course of thermal decomposition of the organic binder in molding sand determines the result in the formation of significant casting defects, knock-out properties or adversely affect the efficiency of thermal reclamation methods of used molding sands [21-25]. In terms of environmental protection and the assessment of the binder's harmfulness, it is also important to determine the quality (composition) of the decomposition products of the binding material released during rapid heating. In this paper, the subject matter related to the explanation of relations between substitution degree and CMS-Na properties in the context of recognition of the degradation process in the binder-sand system subjected to interaction with liquid metal has been discussed. In this work, efforts were made to supplement the knowledge by thermal analysis (TG-DTG-DSC) and pyrolysis-gas chromatography-mass spectrometry (Py-GC/MS) CMS-Na with the degree of substitution in the range of $0.20-0.87$ as a main binder in the molding sand technology.

\section{Experimental}

\section{Materials}

The following samples of CMS-Na with various DS were subjected to thermoanalytical studies:

- Low-substituted CMS-Na $\mathrm{Na}_{\mathrm{L}}$ with DS 0.2; modification by semi-dry method [2],

- Medium-substituted CMS-Na $\mathrm{Na}_{\mathrm{M}}$ with DS 0.5; modification by semi-dry method [2, 12, 26],

- High-substituted CMS-Na $\mathrm{H}_{\mathrm{H}}$ with DS 0.9; modification by slurry method—one step synthesis $[11,12]$.

Moisture content of the starting product was $7.0-8.0 \%$.

\section{Methodology}

\section{Methods of thermal analysis (TG-DTG-DSC)}

Thermal analysis was performed by using a thermal analyzer NETZSCH STA 449 F3 Jupiter ${ }^{\circledR}$ design to simultaneous thermogravimetric (TG), differential thermal analysis (DTG) and differential scanning calorimetry (DSC) measurements, which ensure to obtain independent signals recorded under the same measurement conditions: heating rate, atmosphere and pressure. This method of analysis provided a higher efficiency and allowed obtaining comprehensive information on the thermal characteristics of the samples of tested starch derivatives. The measurement was performed under a nitrogen gas atmosphere in a temperature range of $25-1000{ }^{\circ} \mathrm{C}$ at a gas flow rate of $40 \mathrm{~mL} \mathrm{~min}^{-1}$. The rate of heating of the test sample was $10^{\circ} \mathrm{C} \mathrm{min}^{-1}$.

\section{Pyrolysis-gas chromatography-mass spectrometry (Py-GC/MS)}

The CMS-Na samples (2-4 mg) were thermally degraded in Pyroprobe 5000 pyrolyser (CDS Analytical) in an inert atmosphere (helium). The sample was heated to a set temperature at a rate of $10,000{ }^{\circ} \mathrm{C} / \mathrm{s}$ for a time interval of 3-4 s. Then chromatographic separation (Focus GC, Thermo Scientific) was carried out according to the assumed measurement conditions: Initial heating at $40{ }^{\circ} \mathrm{C}$ lasted for $3 \mathrm{~min}$, then the temperature was increased to $100{ }^{\circ} \mathrm{C}$ (at a rate of $3{ }^{\circ} \mathrm{C} \mathrm{min}{ }^{-1}$ ) and heated for $3 \mathrm{~min}$. Products of pyrolysis were separated on a non-polar TR-SQC tested column ( $30 \mathrm{~m}$ 
length, $0.25 \mathrm{~mm}$ diameter). The next temperature increase to $250{ }^{\circ} \mathrm{C}$ was carried out at the rate of $20{ }^{\circ} \mathrm{C} \mathrm{min}{ }^{-1}$, and the sample was heated for $3 \mathrm{~min}$ at the rate of helium flow in the column of $1 \mathrm{~mL} \mathrm{~min}^{-1}$ and at the division of the sample at the ratio of 1:30. The injector was maintained in the SPLIT mode. The last stage of the study included detection (ISQ, Thermo Scientific) according to the following parameters: ion source temperature $250{ }^{\circ} \mathrm{C}$, electron energy $70 \mathrm{eV}$ at full range $\mathrm{m} / \mathrm{z}$. The qualitative analysis was performed with the use of Xcalibur 2.2 software based on the NIST MS Search 2.0 database as well as on mass spectral data and retention time comparisons reported in literature.

\section{Results and discussion}

\section{Thermal analysis TG-DTG-DSC}

Series of TG, DTG and DSC curves obtained in anaerobic atmosphere for CMS-Na ${ }_{L}$, CMS-Na ${ }_{M}$ and CMS- $\mathrm{Na}_{\mathrm{H}}$ samples are shown in Figs. 1-3.

The parameters that characterize the thermal decomposition are as follows: mass loss $(\Delta m)$, the temperature of maximum rate of mass loss $\left(T_{\text {peak }}\right)$, temperature corresponding to $10 \%$ mass loss $\left(T_{10}\right)$ and the temperature corresponding to $50 \%$ mass loss $\left(T_{50}\right)$, temperature of exo- or endothermic effects occurring in selected temperature range (these parameters are presented in Table 1). On the course of thermal curves, it is possible to determine the subsequent stages of degradation of the binder.

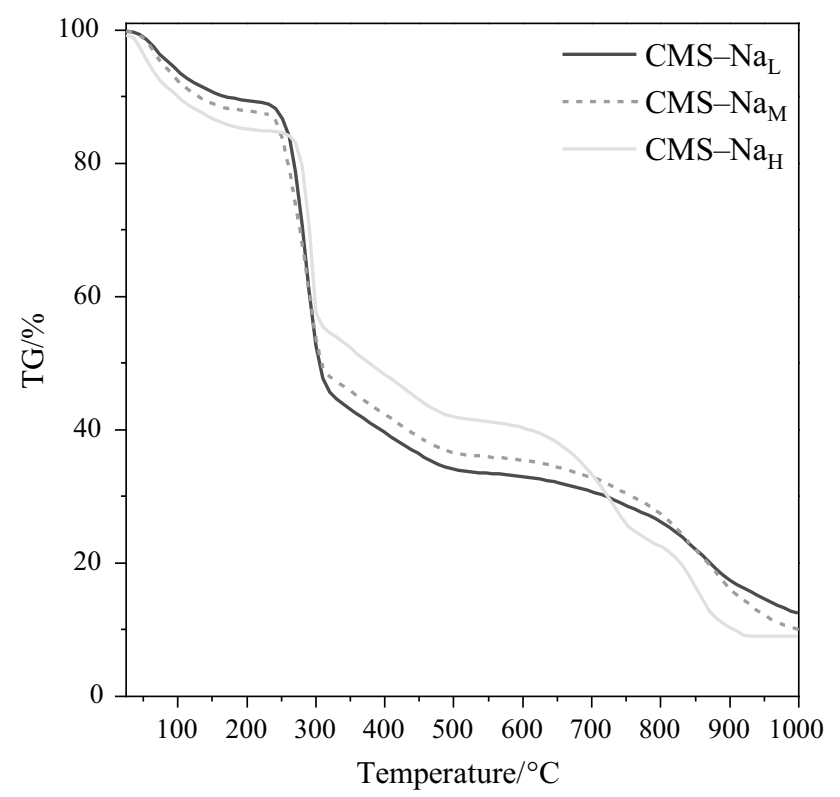

Fig. 1 TG curves of CMS-Na with different degrees of substitution

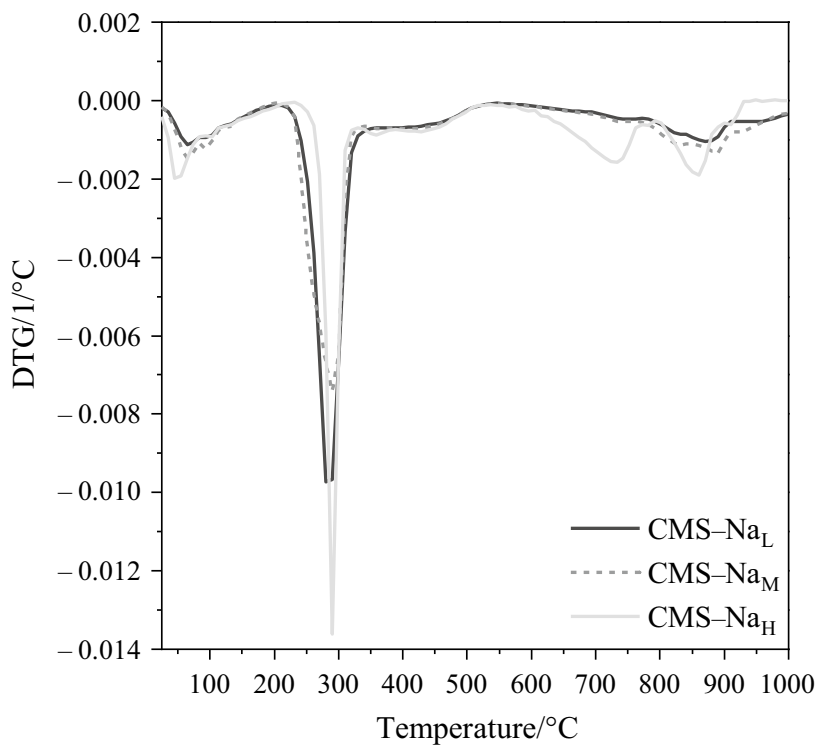

Fig. 2 DTG curves of CMS-Na with different degrees of substitution

The changes in the material due to the rising temperature for CMS-Na samples are multistage (Figs. 1-3). Three mass losses were recorded on the TG curves of CMS- $\mathrm{Na}_{\mathrm{L}}$ : $10.7 \%, 55.7 \%$ and $21.1 \%$ at temperature $63{ }^{\circ} \mathrm{C}, 280^{\circ} \mathrm{C}$ and $871^{\circ} \mathrm{C}$ at which the mass loss rate is maximum (based on DTG curve) and CMS- $\mathrm{Na}_{\mathrm{M}}: 12.2 \%, 51.7 \%$ and $26.1 \%$ with $T_{\text {peak }}$ at $64{ }^{\circ} \mathrm{C}, 291{ }^{\circ} \mathrm{C}$ and $890{ }^{\circ} \mathrm{C}$, respectively. Thermal decomposition of CMS- $\mathrm{Na}_{\mathrm{H}}$ was more complex as it was decomposed with four mass losses of $15.1 \%, 3.6 \%, 17.0 \%$ and $15.2 \%$ with mass loss rate maximum at $45^{\circ} \mathrm{C}, 291{ }^{\circ} \mathrm{C}$, $733{ }^{\circ} \mathrm{C}, 861{ }^{\circ} \mathrm{C}$, respectively. The degradation process of the

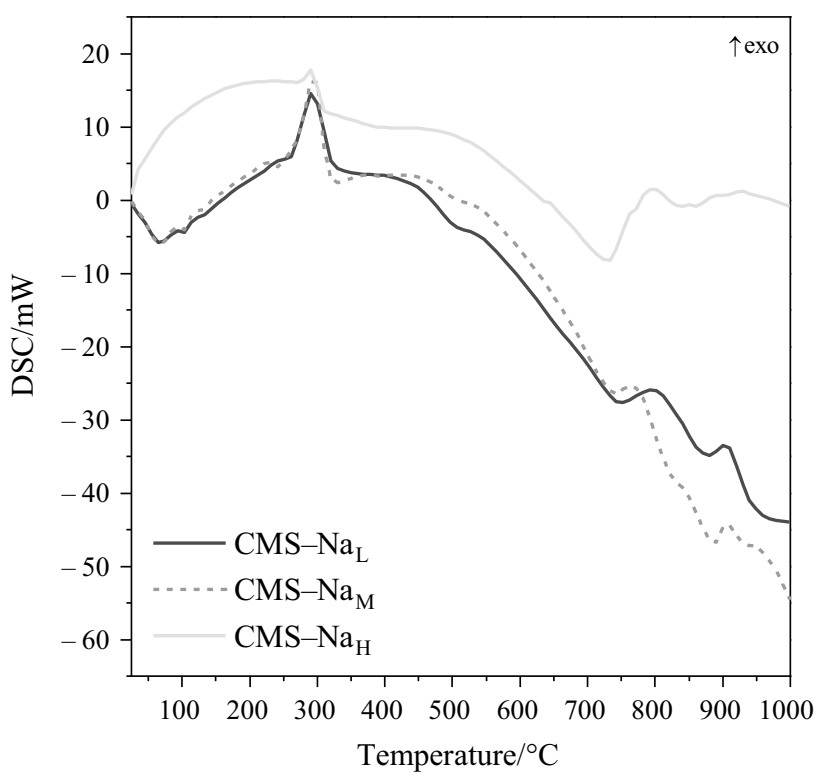

Fig. 3 DSC curves of CMS-Na with different degrees of substitution 
Table 1 Thermoanalytical data (TG, DTG, and DSC) for CMS-Na samples

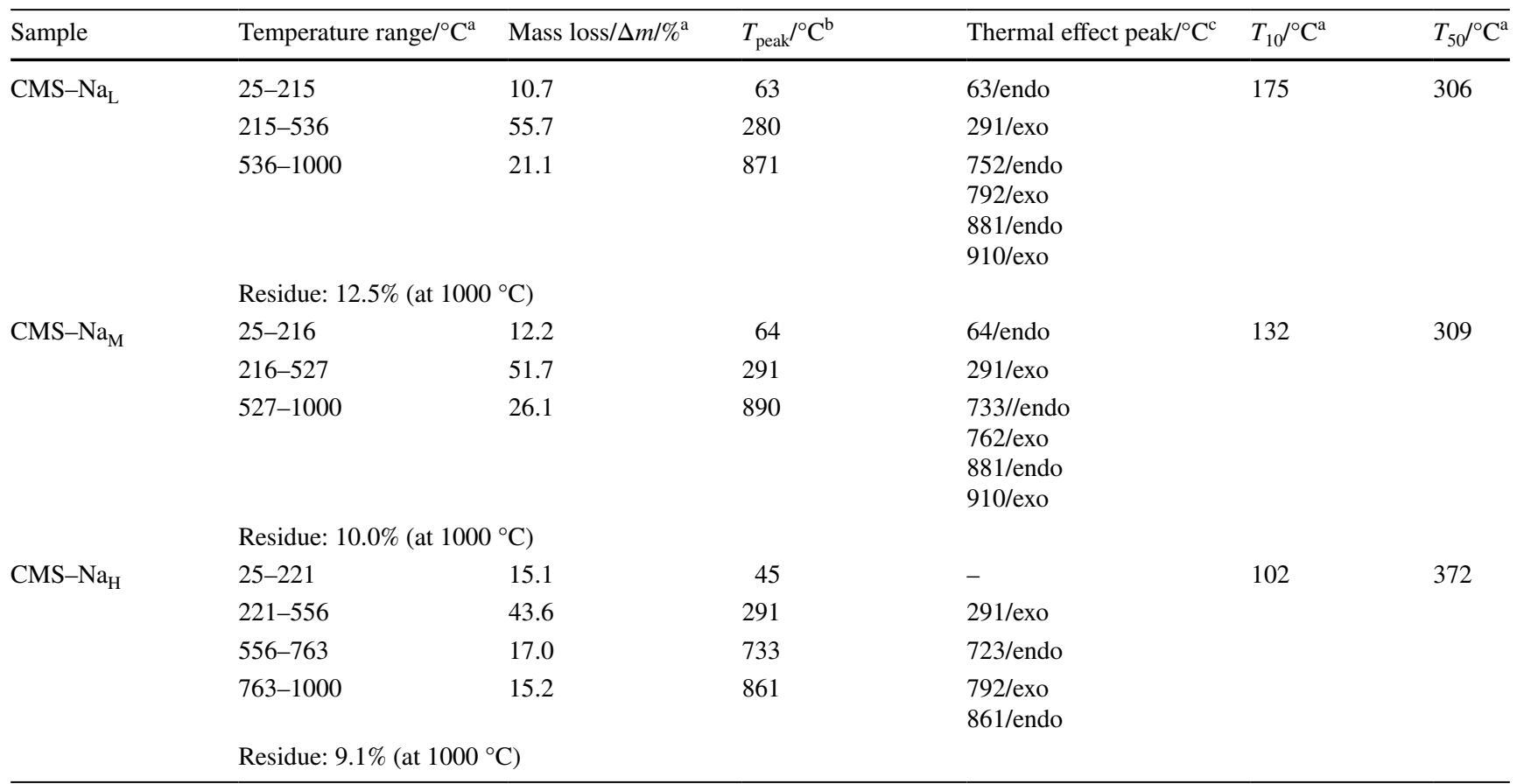

${ }^{\mathrm{a}}$ Based on TG curves

${ }^{\mathrm{b}}$ Based on DTG curves

${ }^{c}$ Based on DSC curves

sodium salt of carboxymethyl starch begins at temperature above $\sim 220{ }^{\circ} \mathrm{C}$. All tested samples in an anaerobic atmosphere were not completely decomposed, and their residue determined at $1000{ }^{\circ} \mathrm{C}$ was $12.5 \%, 10.0 \%$ and $9.1 \%$ for CMS $-\mathrm{Na}_{\mathrm{L}}, \mathrm{CMS}-\mathrm{Na}_{\mathrm{M}}$ and $\mathrm{CMS}-\mathrm{Na}_{\mathrm{H}}$, respectively.

To evaluate and compare the thermal stability of CMS-Na, the parameters $T_{10}$ and $T_{50}$, respectively, were considered. In the case of $\mathrm{CMS}-\mathrm{Na}_{\mathrm{L}}$, mass loss of $10 \%$ is recorded at temperature of $175{ }^{\circ} \mathrm{C}$; comparative measurements to $\mathrm{CMS}-\mathrm{Na}_{\mathrm{M}}\left(T_{10}=132{ }^{\circ} \mathrm{C}\right)$ and $\mathrm{CMS}-\mathrm{Na}_{\mathrm{H}}$ $\left(T_{10}=102{ }^{\circ} \mathrm{C}\right)$, were made. On the other hand, mass losses of $50 \%$ take place until a temperature of $306{ }^{\circ} \mathrm{C}$ is attained in the case of CMS- $\mathrm{Na}_{\mathrm{L}}, 309^{\circ} \mathrm{C}$ for $\mathrm{CMS}-\mathrm{Na}_{\mathrm{M}}$, and $372{ }^{\circ} \mathrm{C}$ for $\mathrm{CMS}-\mathrm{Na}_{\mathrm{H}}$, respectively. Analyzing these mass losses by thermal decomposition, it can be affirmed that the CMS-Na presents a highest thermal stability (higher than that of CMS-Na $a_{L}$ and CMS-Na $a_{M}$ ). The above-mentioned parameter $T_{50}$ confirmed that $\mathrm{CMS}-\mathrm{Na}_{\mathrm{H}}$ has higher thermal stability than in the case of CMS-Na with low and medium substitution degrees; however, this statement should be applied to the temperature range of $\sim 700-720{ }^{\circ} \mathrm{C}$, because observing further changes in the sample above, it was found that CMS $-\mathrm{Na}_{\mathrm{H}}$ is less stable in the range of $730-1000{ }^{\circ} \mathrm{C}$.

On the DSC curves, as shown in Fig. 3 two types of the thermal signals were clearly visible. Three endothermic effects at $63{ }^{\circ} \mathrm{C}, 752{ }^{\circ} \mathrm{C}$ and $881{ }^{\circ} \mathrm{C}$ and three exothermic effects at $291{ }^{\circ} \mathrm{C}, 792{ }^{\circ} \mathrm{C}, 910{ }^{\circ} \mathrm{C}$ were read from the DSC $\mathrm{CMS}-\mathrm{Na}_{\mathrm{L}}$ curve. Endothermic effects at $64{ }^{\circ} \mathrm{C}, 733{ }^{\circ} \mathrm{C}$, $881{ }^{\circ} \mathrm{C}$ and exothermic effects at $291{ }^{\circ} \mathrm{C}, 762{ }^{\circ} \mathrm{C}, 910^{\circ} \mathrm{C}$ were recorded for the $\mathrm{CMS}-\mathrm{Na}_{\mathrm{M}}$ sample. $\mathrm{CMS}-\mathrm{Na}_{\mathrm{H}}$ mass losses were accompanied by two endothermic effects at $723{ }^{\circ} \mathrm{C}$ and $860{ }^{\circ} \mathrm{C}$ and two exothermic effects at $291{ }^{\circ} \mathrm{C}$, $792{ }^{\circ} \mathrm{C}$ and $861^{\circ} \mathrm{C}$ visible as a DSC curve signal.

It was found that the first loss of mass of three CMS-Na samples in the temperature range $25-220{ }^{\circ} \mathrm{C}$ was caused by evaporation of water absorbed on the granules of the starch product and dehydration of the material above $100{ }^{\circ} \mathrm{C}$ (the small endothermic peaks on DSC curves indicate this).

The second significant loss in the temperature range $\sim 220-550{ }^{\circ} \mathrm{C}$ was attributed to the fragmentation of polymer 
chains, cracking of $\mathrm{C}-\mathrm{O}-\mathrm{C}$ bonds in the glycosidic bond (bonds between starch repeat unit in polymer chain), opening of glucopyranose rings and formation of volatile compounds (e.g., $\mathrm{H}_{2} \mathrm{O}, \mathrm{CO}, \mathrm{CO}_{2}$ ), as confirmed by literature data [27-29].

Irreversible changes in the structure of the CMS-Na sample were recorded at $280-290{ }^{\circ} \mathrm{C}$ (in this temperature range the maximum rate of changes and a strong exothermic effect were observed; moved to higher temperature range if DS was higher). The literature data show that the thermal effect on DSC curves recorded for CMS-Na samples at $\sim 300{ }^{\circ} \mathrm{C}$ is characteristic for natural and modified polysaccharides and is attributed to the formation of volatile products in the process of thermal degradation. Thermal reactions for starch start around $300{ }^{\circ} \mathrm{C}$ with thermal condensation between hydroxyl groups of starch chains to form ether segments and liberation of water molecules and other small molecular species. Dehydration of neighboring hydroxyl groups in the glucose ring also occurred, resulting in the formation of $\mathrm{C}=\mathrm{C}$ bonds or breakdown of the glucose ring $[28,30-32]$.

The next large loss of mass up to $\sim 530-550{ }^{\circ} \mathrm{C}$ for CMS-Na samples was connected with detachment of side groups and further cracking of weak glycosidic bonds. In this temperature range of $220-1000{ }^{\circ} \mathrm{C}$, the mass losses may be associated also with much efficient course of material degradation and detachment of the side groups - $\mathrm{COONa}$ (from substituted groups). The endothermic peaks visible on DSC curves at higher temperature were connected to the breaking of the bonds in the structure of samples and may be associated with a carboxy combustion in an anaerobic atmosphere.

Based on obtained results, it was found that the DS of CMS-Na-average amount of substituted $\mathrm{OH}$ groups in polymer chains-may influence the course of starch decomposition in tested samples, which was also confirmed in other research works in natural and modified polymer systems [30, 31, 33, 34]. So, modified structure and the presence of sodium cation in CMS-Na can play a key role in the thermal processes of high-substituted modified starches, increasing the degradation within a certain temperature range (above $730^{\circ} \mathrm{C}$ ), as has also been observed in other natural materials [30, 33, 35]. In addition, at $1000{ }^{\circ} \mathrm{C}$, the residual mass of CMS-Na samples probably contained carbonized carbon and $\mathrm{Na}_{2} \mathrm{CO}_{3}$ (which formation begins in an anaerobic atmosphere in the temperature range of approx $600-750{ }^{\circ} \mathrm{C}$ [36]).

Table 1 summarizes the characteristic thermal data selected from the TG-DTG-DSC curves for CMS-Na samples.

\section{Analysis of products decomposition}

Based on data obtained from TG-DTG-DSC tests, qualitative analysis of decomposition products released at a selected temperature was performed for CMS-Na samples using the method of pyrolytic gas chromatography coupled with mass spectroscopy (Py-GC/MS). Measurements were conducted at $300{ }^{\circ} \mathrm{C}$ (temperature of strongest exothermic effect), $550{ }^{\circ} \mathrm{C}$ (approximate temperature between the second and third mass loss, see Fig. 1) and $1000{ }^{\circ} \mathrm{C}$ (the maximum temperature). Figures 4-6 show the Py-GC/MS results of the CMS- $\mathrm{Na}_{\mathrm{L}}, \mathrm{CMS}-\mathrm{Na}_{\mathrm{M}}, \mathrm{CMS}-\mathrm{Na}_{\mathrm{H}}$ samples (for retention data and peak identification, see Table 2).

On the basis of the obtained results, it was found that at $300{ }^{\circ} \mathrm{C}$ the decomposition of CMS-Na samples took place with the separation of a few compounds registered with the chosen measurement method (Table 2). It was noted that the

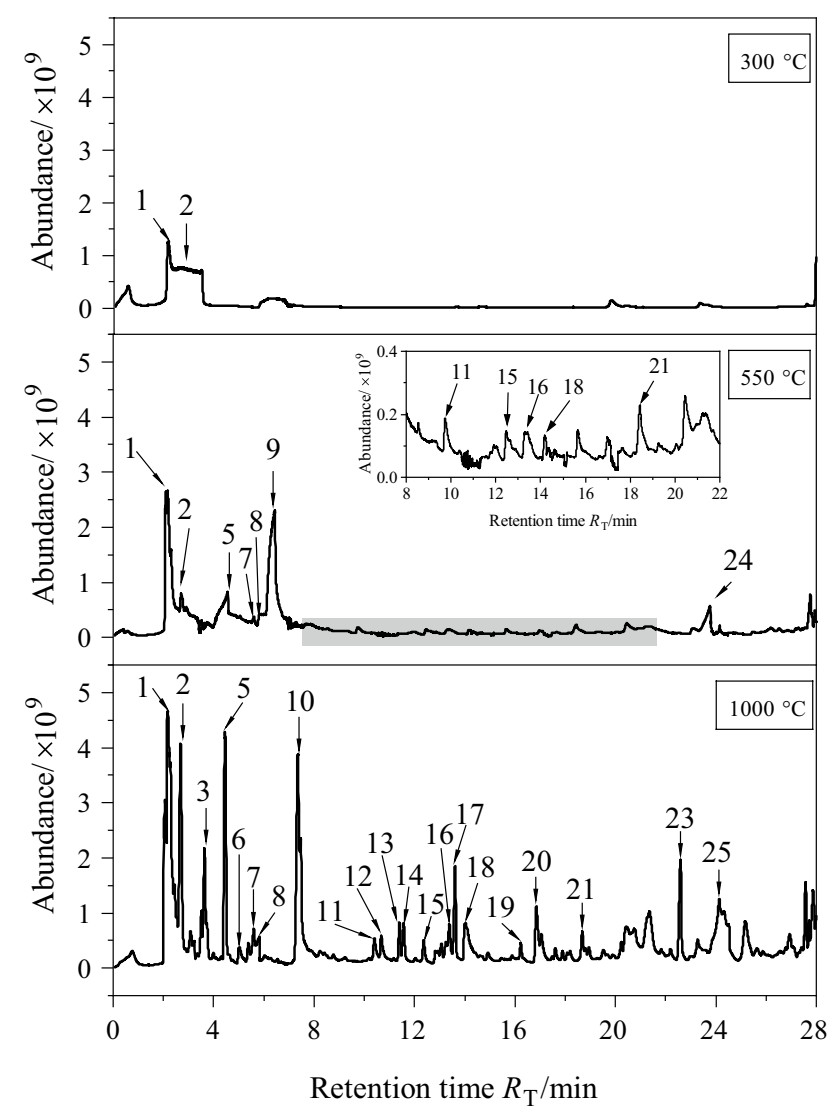

Fig. 4 Py-GC/MS chromatograms of CMS- $\mathrm{Na}_{\mathrm{L}}$ under the different pyrolysis temperatures 


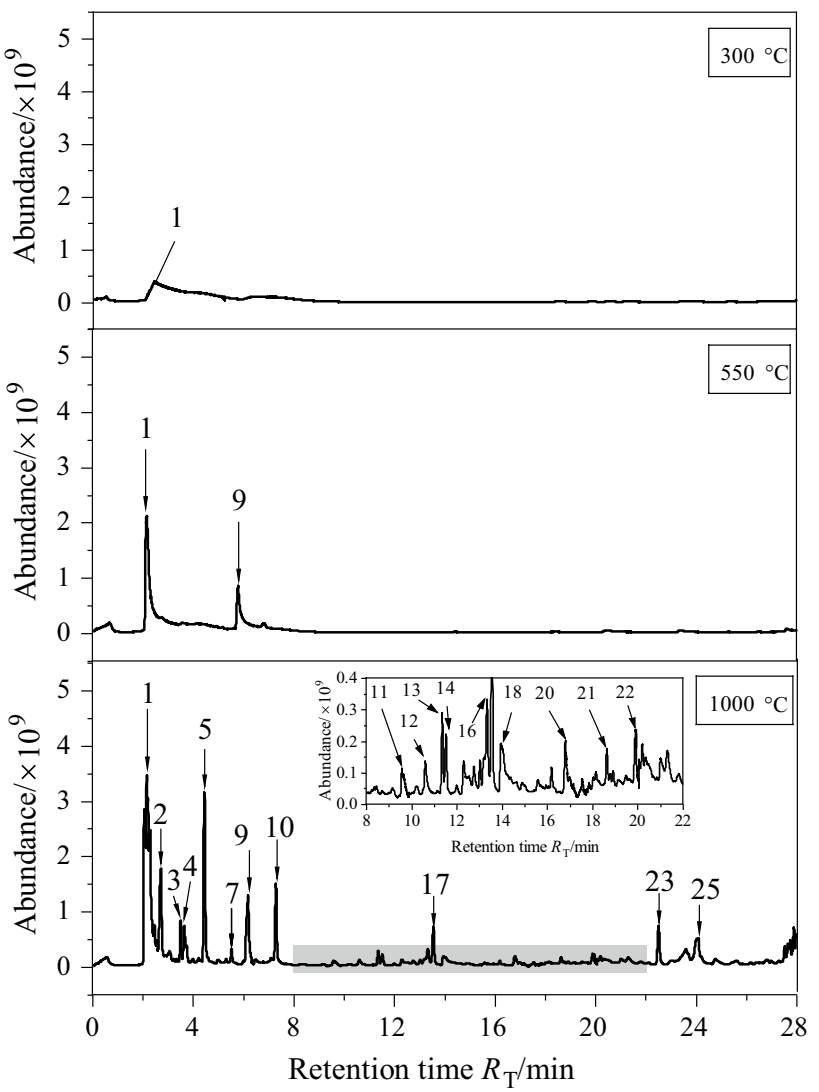

Fig. 5 Py-GC/MS chromatograms of CMS- $\mathrm{Na}_{\mathrm{M}}$ under the different pyrolysis temperatures

signal from these compounds was more intense for samples with lower DS and there were more of them. Small peaks on CMS- $\mathrm{Na}_{\mathrm{L}}$ and $\mathrm{CMS}-\mathrm{Na}_{\mathrm{H}}$ chromatograms were identified as $\mathrm{CO}_{2}$. The course of the $\mathrm{CMS}-\mathrm{Na}_{\mathrm{H}}$ chromatogram indicates that the share of $\mathrm{CO}_{2}$ in degradation products is unnoticeable. Water could be the main product of decomposition below about $300{ }^{\circ} \mathrm{C}$, and $\mathrm{H}_{2} \mathrm{O}$ is formed by inter- and intramolecular condensation of hydroxyl groups in starch chains $[11,37,38]$. So, taking into account the results of thermal analysis indicating a significant mass loss in the range above $\sim 220{ }^{\circ} \mathrm{C}$, with maximum rate at $300{ }^{\circ} \mathrm{C}$, it was found that pyrolysis in $300{ }^{\circ} \mathrm{C}$ could occur with the release of $\mathrm{H}_{2} \mathrm{O}$. However, the column type used in the study does not allow detecting signals from the polar components of the sample decomposition.

The release of cyclic hydrocarbons in the form of, e.g., cyclopenta-1,3-diene, 2-methylcyclopentane-1-one, cyclopent-2-en-1-one and 2,4-dimethylcyclopentane-1,3-dione was observed on chromatograms of CMS- $\mathrm{Na}_{\mathrm{L}}$ sample pyrolyzed at $550{ }^{\circ} \mathrm{C}$. Aromatic hydrocarbons were also formed by

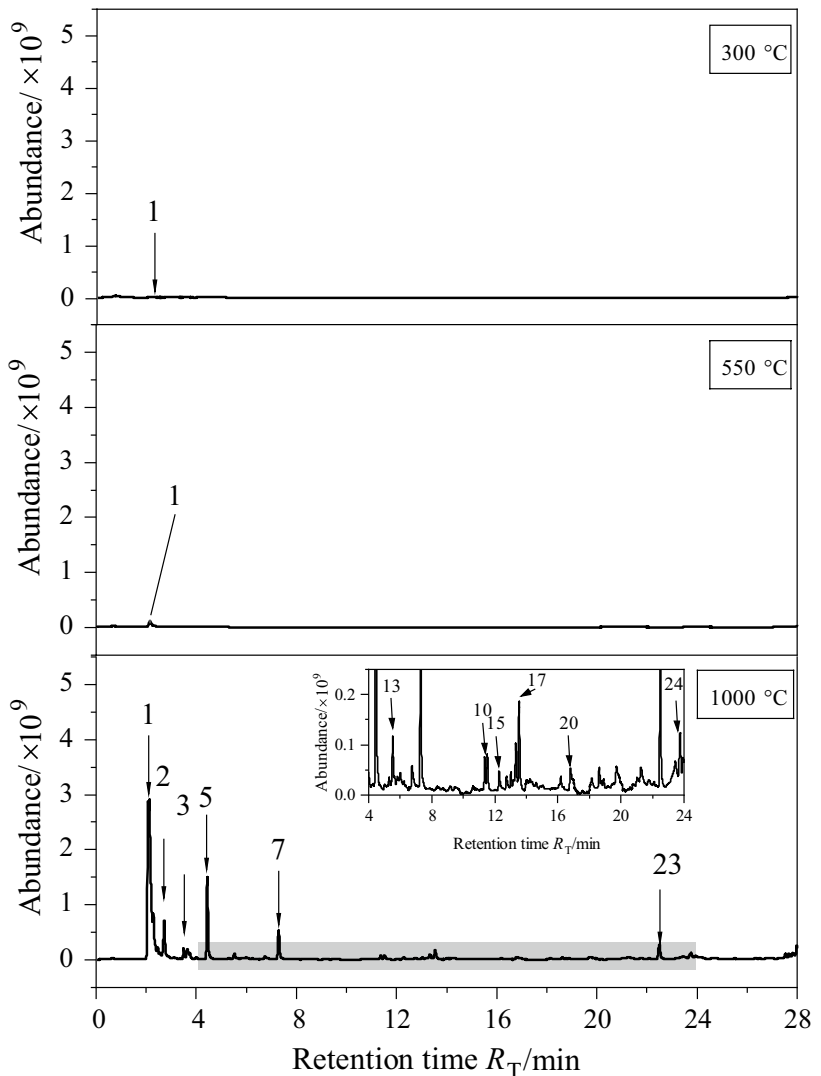

Fig. 6 Py-GC/MS chromatograms of CMS- $\mathrm{Na}_{\mathrm{H}}$ under the different pyrolysis temperatures

decomposition of the low-substituted CMS-Na at $550{ }^{\circ} \mathrm{C}$ in the form of benzene and its derivatives (Table 2). No cyclic or aromatic hydrocarbons were detected in the decomposition products $\mathrm{CMS}-\mathrm{Na}_{\mathrm{M}}$ and $\mathrm{CMS}-\mathrm{Na}_{\mathrm{H}}$ at this temperature.

The identification of carbon dioxide at $1000{ }^{\circ} \mathrm{C}$ indicated the progressive process of decomposition. The presence of benzene, toluene, styrene, phenol and/or their derivatives was found in all CMS-Na degradation products at $1000{ }^{\circ} \mathrm{C}$. Significant intensification of CMS- $\mathrm{Na}_{\mathrm{H}}$ sample decomposition with formation of more degradation products took place at temperatures above $550{ }^{\circ} \mathrm{C}$. At $1000{ }^{\circ} \mathrm{C}$, less number of groups of aromatic hydrocarbons was formed in comparison with $\mathrm{CMS}-\mathrm{Na}_{\mathrm{L}}$ and $\mathrm{CMS}-\mathrm{Na}_{\mathrm{M}}$, which was caused by higher amount of sodium on the course of formation of this type of compounds.

The Py-GC/MS results imply that the increased DS of the samples (polymer with increased content carboxymethyl group with $\mathrm{Na}^{+}$) alters the decomposition course. This conclusion is confirmed by the decreasing amount of the decomposition products with increasing degree of substitution of CMS-Na. 
Table 2 Results of Py-GC/MS measurements for CMS-Na samples at different temperatures

\begin{tabular}{|c|c|c|c|c|c|c|c|}
\hline \multirow[t]{2}{*}{ Peak no. } & \multirow[t]{2}{*}{ Compound (IUPAC name) } & \multirow[t]{2}{*}{ No. CAS } & \multirow[t]{2}{*}{ Molecular formula } & \multirow{2}{*}{$\begin{array}{l}\text { Molecular } \\
\text { weight/u }\end{array}$} & \multicolumn{3}{|c|}{ Retention time $R_{\mathrm{T}} / \mathrm{min}$} \\
\hline & & & & & $\mathrm{CMS}-\mathrm{Na}_{\mathrm{L}}$ & CMS-Na & $\mathrm{CMS}-\mathrm{Na}_{\mathrm{H}}$ \\
\hline 1. & Carbon dioxide & $124-38-9$ & $\mathrm{CO}_{2}$ & 44 & $\begin{array}{l}2.16^{\mathrm{a}} \\
2.17^{\mathrm{b}} \\
2.16^{\mathrm{c}}\end{array}$ & $\begin{array}{l}2.18-2.46^{\mathrm{a}} \\
2.16^{\mathrm{b}} \\
2.16^{\mathrm{c}}\end{array}$ & $\begin{array}{l}2.16^{\mathrm{a}} \\
2.15^{\mathrm{b}} \\
2.13^{\mathrm{c}}\end{array}$ \\
\hline 2. & Cyclopenta-1,3-diene & $542-92-7$ & $\mathrm{C}_{5} \mathrm{H}_{6}$ & 66 & $\begin{array}{l}2.71^{b} \\
2.68^{c}\end{array}$ & $2.72^{\mathrm{c}}$ & $2.72^{\mathrm{c}}$ \\
\hline 3. & Butane-2,3-dione & $431-03-8$ & $\mathrm{C}_{4} \mathrm{H}_{6} \mathrm{O}_{2}$ & 86 & $3.64^{\mathrm{c}}$ & $3.51^{\mathrm{c}}$ & $3.49^{\mathrm{c}}$ \\
\hline 4. & Benzene & $71-43-2$ & $\mathrm{C}_{6} \mathrm{H}_{6}$ & 78 & $\begin{array}{l}4.57^{\mathrm{b}} \\
4.46^{\mathrm{c}}\end{array}$ & $4.46^{\mathrm{c}}$ & $4.44^{\mathrm{c}}$ \\
\hline 5. & (1E)-buta-1,3-dien-1-ol & 70411-98-2 & $\mathrm{C}_{4} \mathrm{H}_{6} \mathrm{O}$ & 70 & $5.02^{\mathrm{c}}$ & - & - \\
\hline 6. & Pentane-2,3-dione & $600-14-6$ & $\mathrm{C}_{5} \mathrm{H}_{8} \mathrm{O}_{2}$ & 100 & $\begin{array}{l}5.60^{\mathrm{b}} \\
5.60^{\mathrm{c}}\end{array}$ & $5.53^{\mathrm{c}}$ & $5.52^{\mathrm{c}}$ \\
\hline 7. & Acetic acid & 64-19-7 & $\mathrm{C}_{2} \mathrm{H}_{4} \mathrm{O}_{2}$ & 60 & $\begin{array}{l}5.86^{\mathrm{b}} \\
5.82^{\mathrm{c}}\end{array}$ & - & - \\
\hline 8. & 1-Hydroxypropan-2-one & $116-09-6$ & $\mathrm{C}_{3} \mathrm{H}_{6} \mathrm{O}_{2}$ & 74 & $6.43^{\mathrm{b}}$ & $\begin{array}{l}5.79^{b} \\
6.19^{c}\end{array}$ & - \\
\hline 9. & Toluene & $108-88-3$ & $\mathrm{C}_{7} \mathrm{H}_{8}$ & 92 & $7.36^{\mathrm{c}}$ & $7.3^{\mathrm{c}}$ & $7.29^{\mathrm{c}}$ \\
\hline 10. & 1-Hydroxybutan-2-one & $5077-67-8$ & $\mathrm{C}_{4} \mathrm{H}_{8} \mathrm{O}_{2}$ & 88 & $\begin{array}{l}9.73^{\mathrm{b}} \\
10.41^{\mathrm{c}}\end{array}$ & $\begin{array}{l}9.49^{\mathrm{b}} \\
9.59^{\mathrm{c}}\end{array}$ & - \\
\hline 11. & Cyclopentanone & $120-92-3$ & $\mathrm{C}_{5} \mathrm{H}_{8} \mathrm{O}$ & 84 & $10.67^{\mathrm{c}}$ & $10.62^{\mathrm{c}}$ & - \\
\hline 12. & Ethylbenzene & $100-41-4$ & $\mathrm{C}_{8} \mathrm{H}_{10}$ & 106 & $11.4^{\mathrm{c}}$ & $11.36^{\mathrm{c}}$ & - \\
\hline 13. & 1,2-Xylene & $95-47-6$ & $\mathrm{C}_{8} \mathrm{H}_{10}$ & 106 & $11.57^{\mathrm{c}}$ & $11.53^{\mathrm{c}}$ & $11.52^{\mathrm{c}}$ \\
\hline 14. & 2-Methylcyclopentan-1-one & $1120-72-5$ & $\mathrm{C}_{6} \mathrm{H}_{10} \mathrm{O}$ & 98 & $\begin{array}{l}12.47^{\mathrm{b}} \\
12.36^{\mathrm{c}}\end{array}$ & - & $12.27^{\mathrm{c}}$ \\
\hline 15. & Ethynylbenzene & $536-74-3$ & $\mathrm{C}_{8} \mathrm{H}_{6}$ & 102 & $\begin{array}{l}13.41^{b} \\
13.39^{c}\end{array}$ & $13.34^{\mathrm{c}}$ & - \\
\hline 16. & Styrene & $100-42-5$ & $\mathrm{C}_{8} \mathrm{H}_{8}$ & 104 & $13.61^{\mathrm{c}}$ & $13.56^{\mathrm{c}}$ & $13.54^{\mathrm{c}}$ \\
\hline 17. & Cyclopent-2-en-1-one & $930-30-3$ & $\mathrm{C}_{5} \mathrm{H}_{6} \mathrm{O}$ & 82 & $\begin{array}{l}14.19^{\mathrm{b}} \\
14.03^{\mathrm{c}}\end{array}$ & $13.97^{\mathrm{c}}$ & - \\
\hline 18. & 1-Ethyl-2-methylbenzene & $611-14-3$ & $\mathrm{C}_{9} \mathrm{H}_{12}$ & 120 & $16.23^{\mathrm{c}}$ & - & - \\
\hline 19. & 2-Methylcyclopent-2-en-1-one & $1120-73-6$ & $\mathrm{C}_{6} \mathrm{H}_{8} \mathrm{O}$ & 96 & $16.85^{\mathrm{c}}$ & $16.81^{\mathrm{c}}$ & $16.8^{\mathrm{c}}$ \\
\hline 20. & 1-Ethenyl-2-methylbenzene & $611-15-4$ & $\mathrm{C}_{9} \mathrm{H}_{10}$ & 118 & $\begin{array}{l}18.44^{\mathrm{b}} \\
18.68^{\mathrm{c}}\end{array}$ & $18.63^{c}$ & - \\
\hline 21. & Phenol & $108-95-2$ & $\mathrm{C}_{6} \mathrm{H}_{6} \mathrm{O}$ & 94 & - & $19.9^{\mathrm{c}}$ & - \\
\hline 22. & 1-Ethynyl-3-methylbenzene & $766-82-5$ & $\mathrm{C}_{9} \mathrm{H}_{8}$ & 116 & $22.59^{\mathrm{c}}$ & $22.52^{\mathrm{c}}$ & $22.49^{c}$ \\
\hline 23. & 2,4-Dimethylcyclopentane-1,3-dione & $34598-80-6$ & $\mathrm{C}_{7} \mathrm{H}_{10} \mathrm{O}_{2}$ & 126 & $23.77^{\mathrm{b}}$ & - & $23.75^{\mathrm{c}}$ \\
\hline 24. & 3-(2-Methyl-2-propanyl)-2,5-furandion & $18261-07-9$ & $\mathrm{C}_{8} \mathrm{H}_{10} \mathrm{O}_{3}$ & 154 & $24.14^{\mathrm{c}}$ & $24.09^{c}$ & - \\
\hline
\end{tabular}

${ }^{\mathrm{a}}$ Compound detected in $300{ }^{\circ} \mathrm{C}$

${ }^{\mathrm{b}} \mathrm{Compound}$ detected in $550{ }^{\circ} \mathrm{C}$

${ }^{\mathrm{c}}$ Compound detected in $1000{ }^{\circ} \mathrm{C}$

\section{Conclusions}

In this paper, thermal degradation properties and effect of pyrolysis of carboxymethyl starch with different DS were analyzed and compared:

1. The results of the TG-DTG-DSC analyses of starch binder CMS-Na show that its thermal decomposition was a multistage process. Degradation of the binder begins at $\sim 220{ }^{\circ} \mathrm{C}$. The subsequent mass losses at temperature range $25-1000{ }^{\circ} \mathrm{C}$ are determined as evaporation of water adsorbed in molecule, sodium carboxymethyl starch dehydration, next breakage of glycosidic bonds in the polymer chains and intensify the fragmentation of chain.

2. Varied thermal behavior was observed for starch samples at temperature above to $220^{\circ} \mathrm{C}$ due to their difference in structural modification. CMS-Na with high DS is more 
stable in temperature up to $\sim 730{ }^{\circ} \mathrm{C}$ than CMS-Na samples with low and medium DS; however, above this temperature the degradation is more intense. At $1000^{\circ} \mathrm{C}$, the samples are not completely decomposed (the remaining mass may stand carbonized carbon and $\mathrm{Na}_{2} \mathrm{CO}_{3}$ ).

3. The thermal decomposition of CMS-Na ${ }_{L}, \mathrm{CMS}-\mathrm{Na}_{\mathrm{M}}$, CMS- $\mathrm{Na}_{\mathrm{H}}$ samples was studied by $\mathrm{Py}-\mathrm{GC} / \mathrm{MS}$ analysis which showed that the chemistry of their degradation was different depending on the degree of substitution. It was shown that the amount of substituted groups in CMS-Na polymer chains (with sodium ion presence) has a significant impact on course of CMS-Na degradation and decreases the tendency to formation of $\mathrm{CO}_{2}$, cyclic and/or aromatic hydrocarbons in the range of $300-1000{ }^{\circ} \mathrm{C}$ for samples with high DS. Therefore, it has been proved that starch etherification does not adversely affect the ecological context of the molding sands under consideration with the participation of CMS-Na.

Acknowledgements The work was supported by Polish Ministry of Science and Higher Education under Dean's Grant AGH UST No. 15.11.170. 643

Open Access This article is distributed under the terms of the Creative Commons Attribution 4.0 International License (http://creativeco mmons.org/licenses/by/4.0/), which permits unrestricted use, distribution, and reproduction in any medium, provided you give appropriate credit to the original author(s) and the source, provide a link to the Creative Commons license, and indicate if changes were made.

\section{References}

1. Zhou X, Yang J, Qian F, Qu G. Synthesis and application of modified starch as a shell-core main adhesive in a foundry. J Appl Polym Sci. 2010;216:2893-900.

2. Zhou X, Yang J, Qu G. Study on synthesis and properties of modified starch binder for foundry. J Mater Process Technol. 2007;183:407-11.

3. Yu W, He H, Cheng N, Gan B, Li X. Preparation and experiments for a novel kind of foundry core binder made from modified potato starch. Mater Des. 2009;30:210-3.

4. Grabowska B, Sitarz M, Olejnik E, Kaczmarska K, Tyliszczak B. FT-IR and FT-Raman studies of cross-linking processes with $\mathrm{Ca}^{2+}$ ions, glutaraldehyde and microwave radiation for polymer composition of poly(acrylic acid)/sodium salt of carboxymethyl starch-Part I. Spectrochim Acta-Part A Mol Biomol Spectrosc. 2015;135:529-35.

5. Grabowska B, Sitarz M, Olejnik E, Kaczmarska K, Tyliszczak B. FT-IR and FT-Raman studies of cross-linking processes with $\mathrm{Ca}^{2+}$ ions, glutaraldehyde and microwave radiation for polymer composition of poly(acrylic acid)/sodium salt of carboxymethyl starch - In moulding sands, Part II. Spectrochim Acta Part A Mol Biomol Spectrosc. 2015;151:27-33.

6. Kaczmarska K, Grabowska B. Potential of the application of the modified polysaccharides water solutions as binders. Metalurgija. 2016;55:15-8
7. Shehu T, Bhatti RS. The use of Yam flour (starch) as binder for sand mould production in Nigeria. World Appl Sci J. 2012;16:858-62.

8. Grabowska B, Sitarz M, Olejnik E, Kaczmarska K. FT-IR and FT-Raman studies of cross-linking processes with $\mathrm{Ca}^{2+}$ ions, glutaraldehyde and microwave radiation for polymer composition of poly(acrylic acid)/sodium salt of carboxymethyl starch - Part I. Spectrochim Acta-Part A Mol Biomol Spectrosc. 2015;131:529-35.

9. Jiang Q, Gao W, Li X, Liu Z, Huang L, Xiao P. Synthesis and properties of carboxymethyl Pueraria thomsonii Benth. starch. Starch/Stärke. 2011;63:692-9.

10. Zhang B, Gong H, Lü S, Ni B, Liu M, Gao C, et al. Synthesis and characterization of carboxymethyl potato starch and its application in reactive dye printing. Int J Biol Macromol. 2012;51:668-74.

11. Spychaj T, Wilpiszewska K, Zdanowicz M. Medium and high substituted carboxymethyl starch: synthesis, characterization and application. Starch/Stärke. 2013;65:22-33.

12. Zdanowicz M, Spychaj T, Lendzion-Bieluń Z. Crosslinked carboxymethyl starch: one step synthesis and sorption characteristics. Int J Biol Macromol. 2014;71:87-93.

13. Bhandari PN, Hanna MA. Preparation of highly substituted carboxymethyl starch using a twin-screw extruder. Starch/Staerke. 2011;63:771-9.

14. Nattapulwat N, Purkkao N, Suwithayapan O. Preparation and application of carboxymethyl yam (Dioscorea esculenta) starch. Am Assoc Pharm Sci. 2009;10:193-8.

15. Hild A, Koch W, Lazik W, Loth F, Volkert B. US 20040039191 A1-Method for producing highly-substituted carboxyalkyl starch. 2001.

16. Tijsen CJ, Voncken RM, Beenackers AACM. Design of a continuous process for the production of highly substituted granular carboxymethyl starch. Chem Eng Sci. 2001;56:411-8.

17. Tijsen CJ, Scherpenkate HJ, Stamhuis EJ, Beenackers AACM Optimisation of the process conditions for the modification of starch. Chem Eng Sci. 1999;54:2765-72.

18. Bi Y, Liu M, Lan W, Cui D. Synthesis of carboxymethyl potato starch and comparison of optimal reaction conditions from different sources. Polym Adv Technol. 2008;19:1185-92.

19. Zhou X, Yang J, Qian F, Guohiu Q. Synthesis and application of modified shell-core main adhesive in foundry. J Appl Polym Sci. 2010;116:2893-900.

20. Zhou X, Yang J, Qu G. Adhesive bonding and self-curing characteristics of $\alpha$-starch based composite binder for green sand mould/core. J MaterSciTEchnol. 2004;20:617-21.

21. Brown J, editor. Sands and green sand. Foseco Ferr Foundryman's Handb. Oxford: Butterworth-Heinemann; 2000.

22. Svidró JT, Diószegi A, Svidró J, Ferenczi T. The effect of different binder levels on the heat absorption capacity of moulding mixtures made by the phenolic urethane cold-box process. J Therm Anal Calorim. 2017;130:1769-77.

23. Svidró JT, Diószegi A, Svidró J, Ferenczi T. Thermophysical aspects of reclaimed moulding sand addition to the epoxy$\mathrm{SO}_{2}$ coremaking system studied by Fourier thermal analysis. J Therm Anal Calorim. 2017;130:1779-89.

24. Grabowska B, Hodor K, Kaczmarska K, Bobrowski A, KurletoKozioł $\dot{Z}$, Fischer C. Thermal analysis in foundry technology. Part 2. TG-DTG-DSC, TG-MS and TG-IR study of the new class of polymer binders BioCo. J Therm Anal Calorim. 2017;130:301-9.

25. Kaczmarska K, Grabowska B, Grabowski G, Bobrowski A, Kurleto-Kozioł $\dot{Z}$. Thermal decomposition of binder based on etherified starch to use in foundry industry: tG-DTG-DSC and DRIFT investigations. J Therm Anal Calorim. 2017;130:285-90. 
26. Spychaj T, Zdanowicz M, Kujawa J, Schmidt B. Carboxymethyl starch with high degree of substitution: synthesis, properties and application. Polimery. 2013;58:501-630.

27. Stojanović Z, Katsikas L, Popovic I, Jovanovic S, Jeremic K. Thermal stability of starch benzoate. Polym Degrad Stab. 2005;87:177-82.

28. Pielichowski K, Njuguna J. Thermal degradation of polymeric materials. London: Rapra Technology Limited; 2005.

29. Worzakowska M. The preparation, physicochemical and thermal properties of the high moisture, solvent and chemical resistant starch-g-poly (geranyl methacrylate copolymers. J Therm Anal Calorim. 2019;9.

30. Rudnik E, Matuschek G, Milanov N, Kettrup A. Thermal stability and degradation of starch derivatives. J Therm Anal Calorim. 2006;85:267-70.

31. Filho GR, de Assunção RMN, Vieira JG, da Meireles CS, Cerqueira DA, da Silva Barud H, et al. Characterization of methylcellulose produced from sugar cane bagasse cellulose: crystallinity and thermal properties. Polym Degrad Stab. 2007;92:205-10.

32. Zdybel E, Tomaszewska-Ciosk E, Romańczuk M. Określenie przewodnictwa cieplnego skrobi różnego pochodzenia botanicznego oraz skrobi ziemniaczanej rozsortowanej według wielkości gałeczek. Biul Inst Hod i Aklim Roślin. 2012;93-100.

33. Fang JM, Fowler PA, Tomkinson J, Hill CAS. The preparation and characterisation of a series of chemically modified potato starches. Carbohydr Polym. 2002;47:245-52.
34. Boki K, Kimura D, Minami K, Yamada Y. Thermal decomposition of sodium carboxymethyl starch. Jpn J Toxicol Environ Heal. 1998;44:204-13.

35. Sebestyén Z, Jakab E, May Z, Sipos B, Réczey K. Thermal behavior of native, washed and steam exploded lignocellulosic biomass samples. J Anal Appl Pyrolysis. 2013;101:61-71.

36. Soares JP, Santos JE, Chierice GO, Cavalheiro ETG. Thermal behavior of alginic acid and its sodium salt. Eclet Quim. 2004;29:57-63.

37. Lee S, Kim ST, Pant BR, Kwen HD, Song HH, Lee SK, et al. Carboxymethylation of corn starch and characterization using asymmetrical flow field-flow fractionation coupled with multiangle light scattering. J Chromatogr A. 2010;1217:4623-8.

38. Mathew S, Abraham TE. Physico-chemical characterization of starch ferulates of different degrees of substitution. Food Chem. 2007;105:579-89.

Publisher's Note Springer Nature remains neutral with regard to jurisdictional claims in published maps and institutional affiliations. 